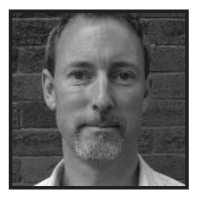

\title{
Stories in Relationship: Experience, Identity, and Curriculum Making in an Elementary Classroom
}

\author{
M. Shaun Murphy, University of Saskatchewan
}

\section{ABSTRACT (Press Here for Sound)}

In this paper the narratives of one teacher and two children show how nested knowing, relational knowing based on personal epistemologies, shaped a narrative understanding of experience and curriculum making in an elementary classroom. Issues of interruptions, ethical tensions, shifts in relationship, and subsequent shifts in knowing are explored. The nested nature of knowing was not only central to the relationship of the teacher and the children, but was also part of the relationships among the children.

n her 1990 paper, "Dilemmas of Knowing: Ethical and Epistemological Dimensions of Teachers' Work and Development," Nona Lyons wrote a small section on the relational knowledge of teachers and children and referred to it as nested knowing. Her ideas on this way of knowing were brief and she ended that small section with a question about what more could be said about the concept. Intrigued by her ideas and interested in understanding this kind of knowing, I included it in my own doctoral research into the lives of a group of children and their teacher in school. As my research progressed, nested knowing became centrally located in my research and I began to focus more on the nested relationship of the children and the teacher who were participants in the inquiry. It became evident to me that the nested nature of knowing was not only central to the relationship of the teacher and the children, but was also part of the relationships among the children. The idea of knowers knowing knowers is complex and multiperspectival. 
There is no simple way to describe nested knowledge. It does not follow a simple domino effect of action and result. Rather, it is more complicated, involving the many relationships that occur in the classroom. It is reminiscent of looking at oneself in a mirror that contains the reflection of another mirror, thus creating an infinite number of reflections. Then imagine adding another set of mirrors at a different angle so that the image becomes even more complex.

Nested knowledge refers to how knowers know knowers. The foundation for this is the epistemological basis of knowledge and the shifts in knowing that can occur as experiences are created that may alter the knower. Lyons used the trope of a web to explain the complexity of the connections. Stories to live by, a narrative term conceptualized by Connelly and Clandinin (1999) to "refer to identity, [and] given meaning by the narrative understandings of knowledge and context" (p.4), provided me with a narrative term for understanding how the members of the classroom contributed to a multi-textured, multi-layered nested knowing within their community. Lyons (1990) wrote, "students and teachers come together in a special relationship in learning, having a clear epistemological basis" (p. 173). In this inquiry it became clear to me that nested knowledge was one way to understand how the teacher and the children shaped each other's story to live by and made curriculum together (Connelly \& Clandinin, 1988). Nested knowledge helped me understand how stories to live by were shifted in the teacher-child relationship.

At the beginning of this inquiry ${ }^{1}$ I initially thought the teacher was the only scaffolding agent for the shifts in the stories to live by experienced by the children in relation to her. However, what became apparent was this was only one dimension of what was occurring. The teacher as a knower of children experienced shifts in her story to live by as she encountered the knowledge of the children, therefore the children were also scaffolding shifts for the teacher. An added dimension is how knowers know themselves by how they are known by others; this both influences their identity composition and the curriculum they are shaping. I used Connelly and Clandinin's (1988) understanding of curriculum as a course of life, rather than the more common understanding based on subject-matter curriculum guides. A contributing factor to the complexity of this web was that children as knowers also knew other children as knowers. In the classroom community the teacher is only one part of this web; she is not the only factor in the shifts that occur within all the relationships in the class which impact nested knowledge. 


\section{Situating the Research and the Method}

At the start of the 2002-2003 school year, I began to work in Lian Elliot's ${ }^{2}$ year five/six classroom ${ }^{3}$ in Ravine Elementary School, which is an ethnically and economically diverse urban school in western Canada. As a doctoral student in educational research, I had negotiated a research relationship that would allow me to position myself as a narrative inquirer alongside Lian and the children for the school year. I was interested in the ways children held and used knowledge about their lives in school (Murphy, 2004). Field texts generated in this narrative inquiry included student work (found poetry, reflective pieces, narrative verse, journals, collages, and other written artefacts), researcher field notes, and transcripts of taped conversations with children, teacher, and the school principal.

Narrative inquiry helped me to explore how individuals understand and talk about their lives and experiences in narrative ways in relation with one another in school. Connelly and Clandinin (2006) referred to the commonplaces of narrative inquiry as time, place, and sociality as a way of understanding experience. These commonplaces framed my understanding of the narratives in the later part of the paper by showing the influence of people, classrooms, and shared history on the experiences. There is an inherent ethical structure in relational narrative inquiry, an important aspect of this inquiry and something that I would encounter in my work with Lian and the children. This meant that I needed to continually negotiate an ongoing, evolving ethical relationship with my participants.

Clandinin and Connelly (2000) helped me consider that epistemology might be understood as an individual's story to live by, the narrative structure (Carr, 1986) by which we make sense of the world, or in relation to epistemology, the ways we know, but as a narrative construct. Teachers and children come together and corresponding shifts occur in their stories to live by. Relationships shape this coming together and are deepened by nested knowing.

For the purpose of this paper I focus on two of the children in the inquiry. Catrina, a girl in year five, and Travis, a boy in year five, helped me understand in diverse ways how their stories to live by were shaped by the contexts of their experiences. Catrina, Travis, and Lian foregrounded how children and teachers negotiate their stories to live by within relationships. Catrina showed me how privileging one telling over another shaped my own story to live by as a researcher. She drew my attention to the ways telling and retelling positions us in relation to others' stories to live by.Travis shaped my understanding of the interconnectedness of our shifting stories to live by and the ways interruptions possibly shift our epistemology and what 
happens when our claims on knowledge are not recognized or honoured. My work with Travis allowed me to see how, as a researcher, I was located within the nested knowledge of the classroom and experienced shifts in my own knowing. The way in which Lian confronted him showed how she was attending to a curriculum of preparation or intentionality in her work and how she imagined him in contexts other than her own classroom.

\section{Nested Knowledge and Curriculum Making}

Lian's nested knowledge of her students helped her scaffold curriculum and experiences with them in school. It could be suggested that she was also scaffolding epistemological shifts, but it was difficult to judge if a child's epistemology had shifted. Certainly the students' knowledge shifted, but can the same be said about their way of understanding knowledge? This inquiry into the epistemological basis for nested knowing would indicate that, as knowers know knowers, small shifts did occur. Thinking about how nested knowledge and experience influence each other invited me to consider how the children and the teacher experienced shifts in what they knew about themselves. This is different than what they know about their knowing. It is a dynamic movement between knowing self, being in relationship, having a pedagogical response, and a subsequent reknowing. The following diagram illustrates the interaction of the three components in a curriculum making (Connelly \& Clandinin, 1988) context.

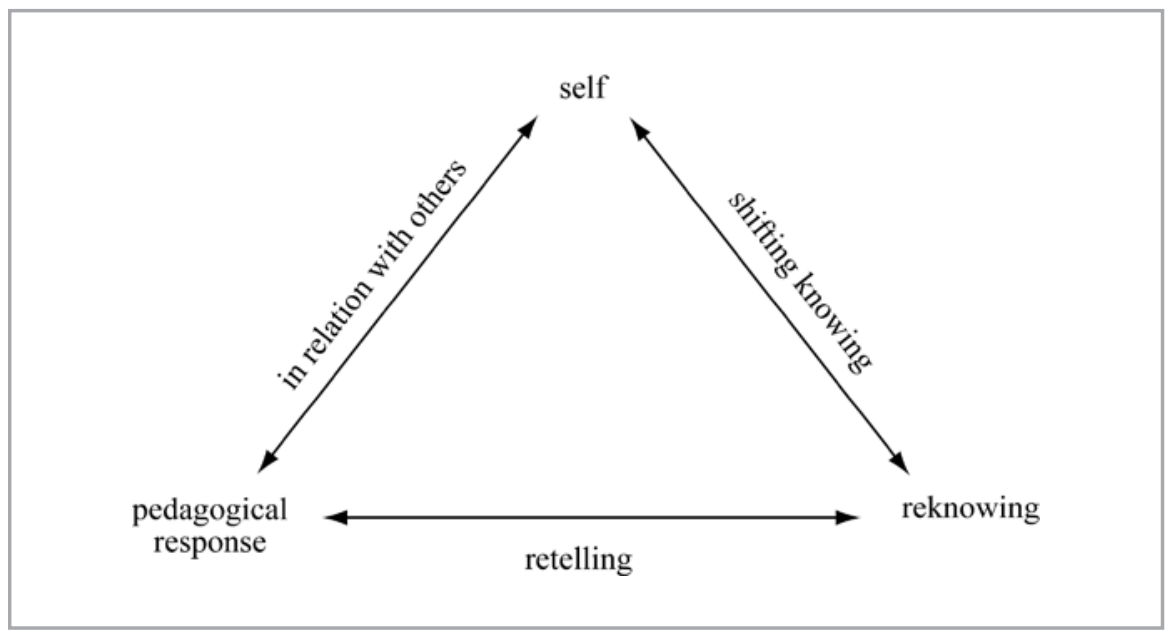

Fig. 1:Three components in curriculum making 
Curriculum in this view is situated in the relational lives of people and is shaped in the shifts that occur when living and working together. In the research narratives in the next section of the paper, the curriculum commonplaces of teacher learner, subject matter, and milieu (Schwab, 1978) all interact to shape experience. The subject matters foregrounded in this paper are not school subjects, but rather the stuff of life with others, what Aoki (2005) referred to as the curriculum-as-lived versus the curriculum-as-planned. This shaped the curriculum of lives for Lian and the children (Clandinin et al., 2006) that occurs "as children's and teachers' diverse lives meet in school" (p. 135).

\section{Working With the Children}

The following narratives situated in Lian's year five/six classroom illustrate how the elements on the diagram interact. I was able to use this diagram to further understand the experiences of the children, Lian, and myself as researcher. When I first began to use the diagram I would place at the top the individual who I assumed was the main character, but as I considered these narratives the "self" in the diagram became each person in the narrative; in each narrative there was no clear one self.My understanding of each narrative became more fluid. The diagram helped me understand experience in Dewey's (1997) terms of context and continuity and Clandinin and Connelly's (2000) narrative terms of living, telling, retelling, and reliving.

\section{A Curriculum of What Is (not): Shifting Knowledge and Ethical Dilemmas}

One day when I arrived at school Lian shared that Catrina had told her and some of the girls in class that she was Leo's ${ }^{4}$ girlfriend and they were going to a convenience store close by after school that day. Lian expressed her concern that Catrina was opening herself to more teasing from the girls. When Lian talked to Leo, a year six boy in the class, about it he denied anything was going on. When she talked to Catrina about it Lian told her she should not be making up stories that would encourage other students in the class to tease her. When I talked to Catrina about the incident she told me a different version about the convenience store and Leo.

Catrina Well what happened is me and Leo were supposed to go to the [convenience store] over, over after school.

Shaun: Yeah.

Catrina: And so I got so excited about that that I told a lot, two of my friends and the teacher that he was my new boyfriend. 
Shaun: Yeah.

Catrina: And it's none of her, it's none of anyone's business if it like if I have a boyfriend or not but I just told them because I trusted them.

Shaun: Yeah.

Catrina: Miss Elliot told him and our plans got cancelled and so Leo ended up lying and I got in trouble.

Shaun: And how did Leo lie?

Catrina: Well like you said, he never said that he said, and he said he said no. And he didn't. (individual taped conversation, February 5, 2003)

It was evident in this conversation that Catrina felt betrayed by both Lian and Leo. Catrina felt betrayed when Lian confronted Leo and chose to believe his version and his denial of the pending meeting at the convenience store. Catrina had decided Leo was her new boyfriend because he had agreed to go to the convenience store after school and let her buy him candy. It was understandable from Leo's point of view that they were not boyfriend and girlfriend; they had only decided to go to the store together. When Leo denied this, he confirmed Lian's suspicions that Catrina was telling a fiction. In this moment Lian privileged Leo's version over Catrina's based on her knowledge of the two of them in school. Another way of understanding this might be to say that Lian used her nested knowledge to understand a story taking place in the class. However, in this instance this nested knowledge was based on what Lian perceived to be true, rather than empirical evidence from both students. Leo, who denied the story, and Catrina, who did not refute it, aided her in this misunderstanding. Perhaps they did this because of their knowledge about the power of teachers in school, even though this was not the typical story of Lian in the classroom. However, it was still a component of her story to live by with the children.

When I talked with Lian later in the year about the convenience store episode we discussed how Leo had scaffolded a shift in Catrina's story to live by denying the story,

Shaun: Because in a sense you could say that Leo scaffolded an experience for Catrina when he sort of ditched her over the ... convenience store.

Lian: Yeah well that's my fault too. (individual taped conversation, May 15, 2003)

In her willingness to understand her role in the convenience store story, Lian accepted the fallibility of her knowledge of Catrina. This understanding began to 
shape the ways Lian and I responded to stories of and stories by Catrina. By being able to hear the more complex version from Catrina, Lian and I were able to retell this story in a way that honours Catrina; being able to understand Catrina in a different manner provides an opportunity for reliving alongside her and in the possibility for a different pedagogical response.

Curriculum making in this moment is a nested event with Catrina, Lian, and Leo playing key roles. As they interact, they all cause shifts in each others' knowing and impact the stories to live by of each person. Later, I too enter the model by returning to the moment with Lian and considering how she was influenced by Catrina and Leo's stories to live by. This moment influences the following narrative as I consider who owns a narrative moment.

In another story of Catrina, Lian recounted how she had put on a CD by a popular female singer that Catrina had brought to school. Many of the girls in class had come up to dance close to Lian's desk. Catrina had joined this group, but according to Lian had danced only on the edges and separate from the community of the other girls. When Lian told the story, Catrina was positioned as an outsider. When I talked to Catrina about the event, she told the story of dancing among the girls, and of singing along with another girl. Initially it was Lian's story that shaped my understanding of the event, the version I took to be true. However, upon reflection, I saw how the story was true for Catrina; the experience belonged to her and, therefore, was hers to interpret. In privileging Lian's version over Catrina's, I was culpable. This was not unlike Lian's privileging of Leo's telling of the convenience store episode. In our work together Lian and I scaffolded for each other a different story to live by in relation to the stories of Catrina. This drew my attention to the ways we privilege the tellings of some over the tellings of others. It highlighted the ethical nature of my relationship among my participants as the receiver of multiple tellings and the ways I needed to negotiate this among them. Catrina helped me begin to understand the ways in which privileging stories influenced my understanding of the lives of children and shaped my nested knowledge of them in school. I became aware of how I had become part of the web of knowing in the classroom. These two stories show how we shifted our knowing in relationship with each other and found possibilities for retelling and reknowing.

For me, as the researcher in this relationship this reknowing and subsequent retelling taught me about the complexities of the narratives we have the privilege of hearing. These moments with Catrina and Lian interrupted my way of thinking about Catrina. The tension for me was in the trajectory I had taken for granted in the ways I 
understood Catrina and the power I accorded Lian's telling of Catrina's experience. The possibility for a shift in pedagogical response lay in how I could attend to the unfolding narratives of my own children in the classrooms in which I taught. I am left to wonder about Catrina's curriculum making and identity composition in relation to the other people in her classroom.

\section{Relationship Shifts Cause Epistemological Shifts: Lian and Travis}

Travis and I, like the other children in the inquiry, had direct conversations about nested knowledge. His conversations about relationship moved in and out of an understanding of nested knowledge. Much of what he talked about in his relationship with Lian could be thought about in terms of nested knowledge. Their history together provided a basis for understanding Travis as a learner and for Travis to understand Lian as a teacher. This meant they had a history of knowing each other as knowers in the context of school. For Travis this history meant she understood him personally and academically.

His understanding of how she knew him as a knower meant she knew he liked sports, that he was "sporty." When I asked him more pointed questions he told me she would know he was not good at mathematics. When I asked what this would mean to her as a teacher his response was she would give him more sheets to make him better at it. Pushing at this I brought their history into the conversation and he told me she had known him "[f]or my whole life" (individual taped conversation, December 12, 2002). Lian had not known him for his whole life and Travis qualified that statement with "in this school she's known me."

Lian had, indeed, known Travis for his whole life in school. She knew his mom, brother, and sister. He thought that knowing his family would help him, "maybe." Then the history of Travis as a knower entered into the conversation. When I asked, "Why do you think teachers need to know things about their kids?" Travis told me, "So that they can help them on their like report cards, um, e-mail people like how good these people are and all that" (individual taped conversation, December 12, 2002). This made him feel safe academically. Importantly, in Travis's knowing, nested knowledge helps people know "how good these people are and all that." Safety, at least emotional safety, was important to Travis and was one of the ways Lian responded to him. He was the boy she wanted in her class, the boy she felt it important to attend to in relation to his need for nurturing. Lian's classroom was a safe place in which to make curriculum and compose an identity. 
Lian was aware of her need to prepare the children with whom she worked for the transition to and their life in junior high, years seven to nine, where the children would experience multiple teachers within a school day. For Lian and the children this could be considered a curriculum of preparation. Throughout the year Lian often spoke of how she felt responsible or worried about how the children would do in the different structure of junior high school. This came up in conversations about many of the children in the inquiry. As the year progressed it also became evident to her that Travis could be at risk in the junior high setting.

Lian had become aware over time of Travis's difficulty in completing tasks and the ways he used his relationship with Lian to avoid some of his work. Lian began to wonder if requesting him in her classroom had been in Travis's best interests. In reaction to his work habits and also to her knowledge that due to a personal move in her future Travis would have a new teacher for year six, Lian began to demand more from Travis and eventually confronted him halfway through the year about his work.

I had a long conversation with Travis about this moment, which I edited for the purpose of this paper. When I told Travis I was aware of what had happened with Lian he replied, "See, that's hard." A comment that led to him telling me it was uncomfortable for him knowing that I knew, “Well first of all, well this isn't about that but sometimes when people tell other people about things I get angry ... what she told you, that was my and her business" and that she had talked to him in "kind of a strange voice ... Well she talked to me the way she hasn't ever talked to me ... it was kind of rude" (reconstructed field text from individual taped conversation, February 13 , 2003). During our conversation he repeated that he wanted to move to a new school. His words about my knowing placed me once again in the space of ethical tension. Lian asked me to talk to him about the incident. She did this relying on the strength of my relationship with Travis. She felt it would be good for him to talk about it. During my conversation with Travis I told him that that had been the intention behind her telling me.

It was important for my relationship with Travis that I talk about the tensions I felt around our conversation and my knowledge of his confrontation with Lian.

Shaun: ... so that was a cool conversation. I liked that. But it was hard wasn't it? It was hard for me too. Do you know why it was hard for me?

Travis: Why?

Shaun: Because I was aware that it was a private thing for you. Because you told me that at the beginning and I wanted to make sure that I was respectful of your privacy. So did I do a good job? Yeah? 
Travis: Yeah.

Shaun: OK. So that was hard for me too. OK. But I feel pretty good about it now.

Travis: For once it's hard for you.

(individual taped conversation, February 13, 2003)

What emerged in this for me was the understanding that Travis did not think I experienced tensions around our conversations. I thought it important he know that I did experience tensions not only in relation to this conversation, but also to others we had had, in which I refer to what Travis and I call the "really big story" - a story he told me about, and one of which I told him that while I would not talk about the details, I would talk about how "really big stories" shape our experiences.

In the unpacking of this moment it became evident how Travis had experienced a shift in how he knew, epistemologically speaking, or in narrative terms, his story to live by, in relation to school and Lian. This shift or interruption was related to Lian's pedagogical shift and influenced Travis's reknowing and relationship with others. It also highlighted for me the nested quality of my relationship with the children and Lian in the inquiry. Lian was hopeful that my relationship with Travis would help him shift his anger. Travis showed me how my knowing of him was situated in our research relationship and I helped Travis understand how his work with me shaped how I knew myself within the research relationship.

In these two moments I was able to see how nested knowing shaped the stories to live by of all the research participants, including myself. It showed me how children compose their stories alongside, or within, the plotlines teachers construct for them. Their experiences together construct their curricula, both real and imagined, as we see in the work of Lian as their teacher. The use of the diagram helped me see the relation between the people in the narratives and the ways their knowing was shaped.

These conversations also shaped an understanding for me of the ethical negotiations necessary among researchers, children, and teachers when they live relational lives within the parameters of the research. It highlights the nested nature of the research relationship and upon reflection draws my attention to my position within the web of knowledge that exists as part of the classroom. In relation with these children and Lian, my knowledge was nested in the knowing they generated around these moments in school. Lian was an active agent in these children's stories to live by as she composed and interpreted their actions, prepared them for different 
teachers and school contexts, and tried to protect them, whether erroneously or correctly with her curriculum of intentionality.

\section{An Opportunity for Retelling}

Catrina's story highlights how ethical questions, such as whose story we privilege in school, provide or do not provide opportunities for retelling. Catrina desired a story of belonging. She tried in the moments shared in this paper to retell who she was in relation to her class and the people within it. In her story of Leo and the convenience store, Lian's interruption repositioned all of us in relation to it. My subsequent retelling then repositioned Lian, although with no subsequent follow-up with Catrina by Lian, Catrina's story remains interrupted. In the story of dancing with the girls in Catrina's telling, Catrina's version remains uninterrupted and it is I, the researcher, who is left to make shifts in my knowing, not only my knowing around the details of the story, but also in my knowledge of how I privilege some stories above others. Lian and Catrina shifted my epistemology in important ways in relation to my story to live by as a narrative researcher in an ethical relationship with participants. When I place myself in the space of dynamic tension between self, pedagogical response, and reknowing I am able to understand my own epistemological shifts.

With the story of Travis, I inquired into this interconnected shifting of stories to live by which happens when knowledge claims are questioned or ways of knowing are no longer allowed. In this research moment Lian and I positioned me as a mediator of relationships. Having learned from Catrina, I trod carefully in the place of privilege I was accorded in the stories to live by of Travis and Lian. Living in relationship as a researcher with these people meant I had to accept the ways I was responsible for their nested knowing and my own. I had become, to borrow Lyons' (1990) web trope, a strand within this classroom, and when another strand on the web was plucked, I felt the vibrations as surely as they felt mine. I do not know how deeply Lian's story was shifted by her interruption of Travis's story, but it is evident in the field texts that Travis's was, and upon reflection, mine was, too. It highlighted the ways I lived in relation with this class and provided powerful moments of teacher education for me.

Nested knowing was sustained and interrupted by the stories of others that existed within the tensions of this classroom. My year in this classroom drew my attention to the ways our stories to live by, our epistemologies, are shaped in relationship and how this influenced curriculum for the children and Lian. The tensions around the interwoven nature of these classroom stories to live by provided 
transformative possibilities for the children, the teacher, and me. They were instrumental in broadening my understanding of the ethics surrounding the privileging of some stories over others, and in causing me to consider the ways nested knowing shaped all of our stories to live by. This also highlighted the ways the stories to live by shaped the curriculum making of individuals and communities. It drew my attention to the ways a curriculum of preparation, often decided upon by a teacher, might interrupt children's identity and curriculum making.

\section{Notes}

1. This research was supported by a Social Sciences and Humanities Research Council grant held by F.M. Connelly and D.J. Clandinin.

2. Pseudonyms are used for the teacher, students, and the school in this paper.

3. Because of the multi-age organization at Ravine Elementary School, the research site, I refer to the children's year in school rather than grade. Year 5/6 refers to the diverse group of 10-, 11- and 12-year-old children in the classroom.

4. Leo was a year six boy in the same classroom as Catrina.

I would like to thank Anne Murray Orr for her careful reading, insightful comments, diagram concept, and her notes in the margin.

\section{References}

Aoki, T. T. (2005). Legitimating lived curriculum: Toward a curricular landscape of multiplicity. In W. Pinar \& R. L. Irwin (Eds.), Curriculum in a new key: The collected works of Ted T. Aoki (pp. 199-215). Mahwah, NJ: Lawrence Erlbaum Associates Publishers.

Carr, D. (1986). Time, narrative, and history. Bloomington: Indiana University Press.
Clandinin, D. J., \& Connelly, F. M. (2000). Narrative inquiry: Experience and story in qualitative research. San Francisco: Jossey-Bass.

Clandinin, D. J., Huber, J., Huber, M., Murphy, M.S., Pearce, M., Murray-Orr, A., et al. (2006). Composing diverse identities: Narrative inquiries into the interwoven lives of children and teachers. London: Routledge. 
Connelly, F. M., \& Clandinin, D. J. (1988). Teachers as curriculum planners: Narratives of experience. New York: Teachers College Press.

Connelly, F. M., \& Clandinin, D. J. (1999). Shaping a professional identity: Stories of educational practice. New York: Teachers College Press.

Connelly, F. M., \& Clandinin, D. J. (2006). Narrative inquiry. In J. Green, G. Camilli \& P. Elmore (Eds.), Handbook of complementary methods in education research (pp. 375-385). Mahwah, NJ: Lawrence Erlbaum.

Dewey, J. (1997). Experience and education. New York:Touchstone.
Lyons, N. (1990). Dilemmas of knowing: Ethical and epistemological dimensions of teachers' work and development. Harvard Educational Review, 60(2), 159-180.

Murphy, M. S. (2004). Understanding children's knowledge: A narrative inquiry into school experiences. Unpublished Dissertation/ Thesis, Unpublished, University of Alberta, Edmonton.

Schwab, J. J. (1978). The practical: Translation into curriculum. In I. Westbury \& N. J.Wilkof (Eds.), Science, curriculum, and liberal education: Selected essays (pp. 365-383). Chicago: University of Chicago Press.

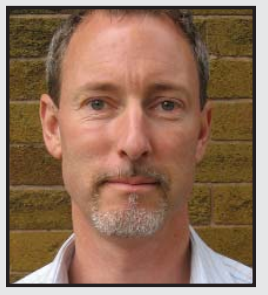

M. Shaun Murphy is currently an Assistant Professor at the University of Saskatchewan in curriculum studies. He has worked alongside children in elementary classrooms for over twenty years. His research focuses on how teachers and children construct curriculum together and the ways they shape each other's experience in schools. 